\title{
Investigating the mixture and subdivision of perceptual and conceptual processing in Japanese memory tests
}

\author{
ROBERTO CABEZA \\ University of Tsukuba, Tsukuba, Japan
}

\begin{abstract}
The dual nature of the Japanese writing system was used to investigate two assumptions of the processing view of memory transfer: (1) that both perceptual and conceptual processing can contribute to the same memory test (mixture assumption) and (2) that both can be broken into more specific processes (subdivision assumption). Supporting the mixture assumption, a word fragment completion test based on ideographic kanji characters (kanji fragment completion test) was affected by both perceptual (hiragana/kanji script shift) and conceptual (levels-of-processing) study manipulations. The significant levels-of-processing effect apparently stems from the conceptual nature of kanji fragments, because it did not occur with the use of meaningless hiragana fragments. The mixture assumption is also supported by an effect of study script on an implicit conceptual test (sentence completion), and the subdivision assumption is supported by a crossover dissociation between hiragana and kanji fragment completion as a function of study script.
\end{abstract}

Depending on their instructions, memory tests can be classified as explicit or implicit. Whereas explicit tests require subjects to retrieve previously studied items, implicit tests do not mention the study episode and measure retention indirectly as a facilitation of performance on a seemingly unrelated task. This facilitation is known as priming. ${ }^{\text {. }}$

Memory tests can be also classified as perceptual or conceptual. Whereas the cues of perceptual tests (e.g., d_n_sa_r) have a perceptual relation with their targets (e.g., dinosaur), the cues of conceptual tests (e.g., reptiles) have a conceptual one. The implicit/explicit and perceptual/conceptual classifications can be combined to yield four kinds of tests: implicit perceptual tests (e.g., word fragment completion); implicit conceptual tests (e.g., category association); explicit perceptual tests (e.g., graphemic cued recall), and explicit conceptual tests (e.g., semantic cued recall). Free recall and recognition are usually classified as explicit conceptual tests.

The foregoing classification is supported by numerous findings of dissociations (for reviews, see RichardsonKlavehn \& Bjork, 1988; Roediger \& McDermott, 1993; Schacter, 1987). The most significant dissociation be-

This research was supported by a scholarship from the Ministry of Education of Japan and is part of a doctoral dissertation submitted to the Doctoral Program in Psychology at the University of Tsukuba. Experiment 2 was reported at the 1993 Annual Meeting of the Japanese Psychological Association. I wish to thank Bradford Challis, Tim Curran, John Gardiner, Peter Graf, Douglas Hintzman, Gail Musen, Nobuo Ohta, Suparna Rajaram, Henry Roediger, Barbara Schwartz, and an anonymous reviewer for their valuable comments on different versions of this paper. Correspondence concerning this article should be addressed to R. Cabeza, Rotman Research Institute, Baycrest Centre, 3560 Bathurst Street, North York, ON Canada M6A 2 E1. tween explicit and implicit tests is the finding that amnesics are greatly impaired on explicit but not on implicit tests (for a review, see Shimamura, 1986). Dissociations between perceptual and conceptual tests have been found mainly as an effect of perceptual and conceptual manipulations. For example, conceptual manipulations, such as levels of processing (e.g., Srinivas \& Roediger, 1990), imagery (Blaxton, 1989), and list organization (Rappold \& Hashtroudi, 1991) tend to affect conceptual but not perceptual tests, whereas perceptual manipulations, such as shifts of modality (e.g., Srinivas \& Roediger, 1990), and surface form (e.g., Blaxton, 1989), typically produce the opposite results.

The processing view (see, e.g., Roediger \& Blaxton, 1987; Roediger \& McDermott, 1993; Roediger, Srinivas, \& Weldon, 1989; Roediger, Weldon, \& Challis, 1989) explains the effects of perceptual and conceptual manipulations on the basis of the transfer-appropriate processing principle (memory performance is a function of the overlap between study and test operations; see, e.g., Morris, Bransford, \& Franks, 1977), and a distinction between perceptual and conceptual processing (see, e.g., Jacoby, 1983). According to this view, conceptual manipulations affect conceptual tests because both emphasize conceptual processing, and perceptual manipulations affect perceptual tests because both underscore perceptual processing. This explanation does not imply that memory tests reflect only one kind of processing, or that perceptual and conceptual processing cannot be divided further. On the contrary, the processing view assumes that most memory tests involve a mixture of perceptual and conceptual processing (the mixture assumption; see, e.g., Roediger \& Blaxton, 1987; Roediger \& Challis, 1992; Roediger \& McDermott, 1993; 
Roediger, Weldon, \& Challis, 1989; Weldon, 1991) and that it is possible to distinguish between types of perceptual processing and types of conceptual processing (the subdivision assumption; see, e.g., Roediger \& McDermott, 1993).

The mixture and subdivision assumptions have received some empirical support. The mixture assumption is supported by conceptual effects on perceptual tests and by perceptual effects on conceptual tests. For instance, significant levels-of-processing (LOP) effects have been found on the implicit perceptual word stem and word fragment completion tests (e.g., Bowers \& Schacter, 1990; Graf, Squire, \& Mandler, 1984; Squire, Shimamura, \& Graf, 1987; Srinivas \& Roediger, 1990; for a review, see Challis \& Brodbeck, 1992), and significant effects of surface form shifts (e.g., typography, case, etc.) have been observed on recognition (e.g., Graf \& Ryan, 1990; Kirsner \& Smith, 1974; Masson, 1984). The subdivision assumption has been buttressed, for example, by Weldon and Roediger's (1987) finding that words produced more priming than did pictures in the word fragment completion test, whereas the converse occurred in the picture fragment identification test. This dissociation suggests a distinction between the perceptual processing of words and the perceptual processing of pictures. The conceptual side of the subdivision assumption has been supported by evidence of a dissociation between two implicit conceptual tests (Cabeza, 1994).

Nevertheless, the amount of evidence supporting the mixture and subdivision assumptions is relatively small, and numerous findings could be explained by adopting the simpler hypotheses that memory tests are normally pure measures of one kind of processing and that the different forms of perceptual (or conceptual) processing produce basically the same transfer effects. Thus, the mixture and subdivision assumptions require further support. The mixture assumption would be supported by evidence that memory tests can reflect both perceptual and conceptual processing, and the subdivision assumption, by dissociations between tests tapping different forms of either perceptual or conceptual processing. The objective of the experiments reported in this article was to find such evidence by taking advantage of the specificity of the Japanese writing system.

Normal Japanese writing is usually a mixture of the three scripts: kanji, hiragana, and katakana; kanji is typically used for nouns and root parts of verbs, adjectives, adverbs, and so forth; hiragana, for inflections and other grammatical parts of sentences; and katakana, for the transcription of foreign words. Like the English alphabet, hiragana and katakana are phonographic scripts in which letters represent sounds-syllable sounds in the case of hiragana and katakana (see the example in Figure lb: $b u, b o, g u$ ). In contrast, kanji is an ideographic script in which characters represent ideas and are only weakly associated with sounds. For example, the word stationery in Figure $1 \mathrm{c}$ is composed of three kanji characters, meaning letter, room, and instrument, respec- tively. (For a more detailed description of Japanese scripts, see Cabeza \& Ohta, 1993; or Paradis, Hagiwara, \& Hildebrandt, 1985.)

The mixture assumption was investigated by exploiting the ideographic nature of kanji characters. The English (e.g., Figure 1a), hiragana (e.g., Figure 1b; see Komatsu \& Ohta, 1984), and katakana (see Komatsu \& Naito, 1992) word fragment completion tests are based on meaningless strings of letters and spaces as cues, and they involve a considerable amount of perceptual processing, but little conceptual processing. In contrast, the kanji fragment completion test (Figure 1c; Cabeza \& Ohta, 1993) seems to involve a substantial amount of both perceptual and conceptual processing. First, some parts of its cues have associated meanings that could affect the completion process. For instance, the part of the second kanji in the fragment in Figure 1c (户) is a kanji itself, and has a meaning (door or house) related to the meaning of the kanji it cues (room). Even if the semantic associations between fragments and targets are not direct, the mere presence of meaningful elements in the fragments is likely to encourage conceptual processing. Second, since the meanings of the kanji composing a word are normally related to the meaning of the word, when one kanji in the cue is completed, it can become a conceptual cue for the target word. In Figure 1c, for example, when the first kanji (letter) is completed, it can aid the completion of the whole word (stationery). ${ }^{2}$ An analogy in the English word fragment completion test would be a fragment like $a_{-} t_{-} o_{-}{ }_{-}$le, after subjects had completed the first two blanks (auto_o__le). Since these conceptual aspects of the kanji fragment completion test do not seem to weaken its highly visual nature, it is reasonable to assume that this test reflects both perceptual and conceptual processing, and to predict that it will be sensitive to both perceptual and conceptual manipulations. Such a result would provide support for the mixture assumption.

The subdivision assumption was investigated by means of a study-test shift between hiragana and kanji scripts (for a hiragana/katakana shift, see Komatsu \& Naito, 1992). This manipulation can be classified as a perceptual manipulation, because Japanese words have the same meaning when written in hiragana or in kanji, and a) STATIONERY

b)

c)

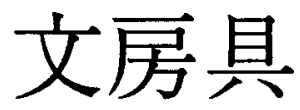

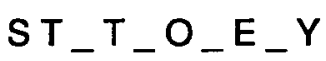
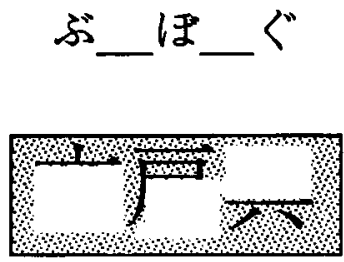

Figure 1. Examples of empty and completed cues of the standard English (a) and Japanese (b) word fragment completion tests, and of the kanji fragment completion test (c). 
as a surface form shift (e.g., typography, font, case) because it does not affect either modality (visual) or symbol type (word). Nevertheless, the script manipulation seems more radical than standard surface form manipulations, because it involves different writing scripts, rather than different versions (e.g., uppercase, lowercase) of the same script (roman letters). However, it does not involve different languages, like the Hindi/Urdu shift studied by Brown, Sharma, and Kirsner (1984), but rather two parallel writing systems of the same language. If the perceptual operations involved in hiragana and kanji processing differ to some extent, it is possible to predict, on the basis of the transfer-appropriate processing principle, that hiragana words would produce more priming than kanji words in a hiragana word fragment completion test, but the opposite would occur in the kanji fragment completion test. Like Weldon and Roediger's (1987) dissociation between a word and a picture test as an effect of a word-picture shift, this crossover dissociation would buttress the subdivision assumption.

Experiment 1 was performed to investigate the effects of the conceptual levels-of-processing (LOP) manipulation on the kanji fragment completion test, the general knowledge test, and the explicit versions of these tests. A significant LOP effect on priming in the kanji fragment completion test was predicted. Experiment 2 was a study of the effects of the LOP and the hiragana/kanji manipulations on the hiragana fragment completion test, the kanji fragment completion test, and the hiragana sentence completion test and its explicit version. It was expected that the kanji fragment completion test would be sensitive to both LOP and script manipulations, and that the script manipulation would produce a dissociation between the hiragana and kanji completion tests. Although many of the results obtained in these experiments could be explained by other theories (e.g., those of Graf \& Ryan, 1990; Jacoby \& Hollingshead, 1990; Squire, 1987; and Tulving \& Schacter, 1990), the discussion of the results is focused on the mixture and subdivision assumptions of the processing view.

\section{EXPERIMENT 1}

Experiment 1 was an investigation of the effects of the LOP manipulation on implicit perceptual, implicit conceptual, explicit perceptual, and explicit conceptual tests. The implicit perceptual test was the kanji fragment completion test (Cabeza \& Ohta, 1993). The implicit conceptual test was the standard general knowledge test (see, e.g., Blaxton, 1989). The explicit perceptual test was the kanji fragment cued recall test, and the explicit conceptual test was the general knowledge cued recall test (see, e.g., Challis \& Sidhu, 1993). These two explicit tests differed from their implicit versions only in retrieval orientation: whereas the instructions for the explicit tests required subjects to complete the cues by using only studied words, the instructions for the im- plicit tests encouraged them to write the first words that came to their minds.

The processing view predicts significant LOP effects on the implicit and explicit general knowledge tests, because their conceptual cues are likely to emphasize conceptual processing. Although the cues of the kanji fragment completion test are perceptual, they also seem to involve an important conceptual component, as discussed before, and hence, the processing view would predict a considerable LOP effect in this test too. The explicit version of this test should be sensitive to LOP, not only because of the conceptual component of the kanji cues, but also because explicit retrieval instructions tend to encourage conceptual processing (e.g., Roediger, Weldon, \& Challis, 1989). Thus, the processing view predicts significant LOP effects on all four tests.

\section{Method}

Subjects and Design. The subjects were 62 undergraduates, who participated voluntarily in the experiment. The experiment had one between-subjects factor, test type (kanji fragment completion, general knowledge, kanjı fragment cued recall, general knowledge cued recall), and two within-subjects factors, item type (semantic, physical, nonstudied), and retention interval (30 min, 1 week). Since memory performance in the 1 -week condition was generally nonsignificant and the retention interval manipulation is not related to the main topic of this article, the data from the delayed condition and the effects of the retention interval manipulation will not be reported or discussed here. Subjects were randomly assigned to the between-subjects conditions (kanji fragment completion, 20 subjects; general knowledge, 16; kanji fragment cued recall, 11; general knowledge cued recall, 15).

Materials. All the materials in Experiments 1 and 2 were exclusively in Japanese - the English examples in this article are approximate translations of the originals. The materials were based on 120 low-frequency two-kanji words selected from word frequency norms for high school textbooks (Kokuritsu Kokugo Kenkyujou, 1983). For each word, kanji-fragment cues and general knowledge questions were constructed. The kanji-fragment cues were created by writing kanji words on a gray background and quasirandomly erasing some kanji parts. The general knowledge questions, similar to the ones used by Blaxton (1989), were constructed partly from dictionary definitions (e.g., What is the name of the tiny openings in the surface of the skin or of a leaf? answer: pore). The kanji-fragment cues and general knowledge questions were modified on the basis of two pilot studies until baseline levels of completion between 0.10 and 0.50 were obtained. With few exceptions, the kanji fragment cues could be completed only with the target words. The general knowledge questions could be answered also with other words, but the target words were usually the only good answers.

The set of 120 words, and their corresponding kanji and question cues, were randomly divided into six sets of 20 items each. Subjects studied four sets and were tested on two of them, plus a set of nonstudied items. Subjects were tested on the other two studied sets and one nonstudied set in the delayed condition. The assignment of the four studied sets to the semantic and physical conditions and of the two nonstudied sets to the nonstudied conditions was varied across subjects. Twenty additional words were selected from the same source to be used as study fillers.

Procedure. The 80 target words plus the 20 study fillers were presented in four lists of 25 words. The first 2 and last 3 words of each list were fillers. The words were presented with the use of a 
slide projector at the rate of one word every $7 \mathrm{sec}$, with an interval of $2 \mathrm{sec}$ between words. Each subject studied two lists under a semantic task and two under a physical study task. In the semantic task, the subjects had, for each word, to think of a sentence and then, using a 5-point scale, to indicate how difficult it was to do so. In the physical task, they had to count or, if time was not sufficient, to guess how many strokes are necessary for writing each word. Each subject received the semantic and physical blocks in one of four possible orders (SSPP, PPSS, SPSP, PSPS).

After the study phase, the subjects listened to a lecture for $30 \mathrm{~min}$ and then received one of four types of tests. Test cues were presented in booklets, with one cue per page. The instructions for the implicit tests directed the subjects to always answer with the first word that came to therr minds, even if some of the words they had seen on the screen might appear among the answers. In contrast, the explicit instructions required subjects to answer only when they could remember one word from the study list that fitted the cue. Each booklet contained 60 words: 40 studied targets ( 20 studied semantically; 20 studied physically), plus 20 nonstudled targets, which provided the estimate of baseline completion. Every 10 sec, a bell rang indicating to the subjects that the time allowed for that cue was over and that they had to turn the page of the booklet to answer a new cue.

\section{Results and Discussion}

In both experiments, the results were analyzed in a similar way. The significance of priming and explicit memory performance was evaluated by performing analyses of variance (ANOVAs) including nonstudied items (e.g., item type: semantic, physical, nonstudied) and contrasting the mean of each studied condition with its corresponding baseline (e.g., semantic vs. nonstudied). The effects of the different factors manipulated (e.g., LOP) were evaluated by conducting ANOVAs on priming and explicit memory scores, obtained by subtracting the baseline from studied conditions (e.g., semantic minus nonstudied). Interactions between factors and tests were sometimes evaluated with ANOVAs including more than one test. The results of this last kind of analysis, however, should be interpreted cautiously, because different memory tests usually involve different measurement scales, with different inherent variability. In both experiments, the significance level was set at .05.

The results of Experiment 1 are presented in Table 1. In the kanji fragment completion test, priming was significant in both the semantic $\left[F(1,19)=62.49, M S_{\mathrm{e}}=\right.$ $1.11]$ and the physical $\left[F(1,19)=16.82, M S_{\mathrm{e}}=0.30\right]$ conditions. In the general knowledge test, priming was significant in the semantic $\left[F(1,10)=15.004, M S_{\mathrm{e}}=\right.$ $0.16]$ but not in the physical $\left[F(1,10)=2.81, M S_{\mathrm{e}}=0.03\right]$ condition. Explicit memory performance in the kanji cued recall test was significant in both the semantic $[F(1,15)=$ $\left.52.71, M S_{\mathrm{e}}=1.26\right]$ and the physical $[F(1,15)=24.17$, $\left.M S_{\mathrm{e}}=0.58\right]$ conditions. In the general knowledge test, explicit performance was also significant in both the semantic $\left[F(1,14)=76.11, M S_{\mathrm{e}}=1.75\right]$ and the physical $\left[F(1,14)=14.37, M S_{\mathrm{e}}=0.33\right]$ conditions.

Confirming the predictions of the processing view, the main effect of LOP on each of the four tests was significant [kanji fragment completion, $F(1,19)=9.75$, $M S_{\mathrm{e}}=0.26$; general knowledge, $F(1,10)=5.65, M S_{\mathrm{e}}=$ 0.05 ; kanji fragment cued recall, $F(1,15)=4.75, M S_{\mathrm{e}}=$ 0.131 ; general knowledge cued recall, $F(1,14)=31.42$, $\left.M S_{\mathrm{e}}=0.56\right]$. The significant LOP effects on the implicit and explicit general knowledge tests are consistent with previous research (e.g., Challis \& Sidhu, 1993; Hamann, 1990). Replicating a finding of Challis and Sidhu's (1993), the LOP effect was greater in the explicit than in the implicit general knowledge test [LOP $\times$ test interaction: $\left.F(1,24)=7.12, M S_{\mathrm{e}}=0.10, p<.02\right]$. This finding is in agreement with the idea that explicit instructions tend to increase conceptual processing (see, e.g., Roediger, Weldon, \& Challis, 1989). The significant LOP effect on the kanji cued recall test is consistent with the results of studies with the word stem and word fragment cued recall tests (e.g., Graf \& Mandler, 1984; Roediger, Weldon, Stadler, \& Riegler, 1992), and, as in those studies, it can be attributed to the explicit nature of the test.

The most important result of Experiment 1 was the significant LOP effect on the kanji fragment completion test. This result is consistent with the idea that the cues of this test involve an important conceptual component, and it supports the notion that memory tests can involve a mixture of perceptual and conceptual processing (mixture assumption). Since the instructions for the kanji fragment completion test are implicit, the form of conceptual processing tapped by this test is probably implicit, such as the one reflected by the implicit conceptual tests. Thus, in Tulving and Schacter's (1990) terminology, the kanji fragment completion test seems to reflect both perceptual priming and conceptual priming.

However, there are three points that require further research. First, a significant LOP effect on the kanji fragment completion test does not imply that this test involves a mixture of perceptual and conceptual processing, only that it involves conceptual processing. To support the idea of mixture of processes, it is necessary to show that the kanji fragment completion test can be simultaneously affected by both perceptual and concep-

Table 1

Experiment 1: Proportion of Correct Completions in the Semantic, Physical, and Nonstudied Conditions, and Levels of Processing (LOP) Effect (Semantic Minus Physical) as a Function of Tests

\begin{tabular}{|c|c|c|c|c|}
\hline \multirow[b]{2}{*}{$\begin{array}{c}\text { Test } \\
\end{array}$} & \multirow[b]{2}{*}{ Semantic } & \multicolumn{2}{|c|}{ Condition } & \multirow{2}{*}{$\begin{array}{l}\text { LOP } \\
\text { Effect }\end{array}$} \\
\hline & & Physical & Nonstudied & \\
\hline Kanji fragment completion & .53 & .37 & .20 & .16 \\
\hline General knowledge & .68 & .58 & .51 & .10 \\
\hline Kanji fragment cued recall & .47 & .34 & .07 & .13 \\
\hline General knowledge cued recall & .65 & .38 & .17 & .27 \\
\hline
\end{tabular}


tual manipulations. Experiment 2 was performed in an attempt to obtain such a finding.

Second, rather than conceptual priming, the significant LOP effect on the kanji fragment completion test could reflect a contamination by explicit retrieval strategies. Some researchers have suggested that significant LOP effects on implicit perceptual tests reflect the uninstructed use of explicit retrieval (e.g., Bowers \& Schacter, 1990; Roediger et al., 1992; Squire et al., 1987; see review by Challis \& Brodbeck, 1992). Nobody has suggested, however, that conceptual effects on implicit conceptual tests (e.g., Blaxton, 1989; Challis \& Sidhu, 1993; Hamann, 1990; Srinivas \& Roediger, 1990) are due to contamination by explicit retrieval; the use of such a hypothesis does not seem necessary when the conceptual nature of the cues can account for the conceptual effect. Thus, if the significant LOP effect on the kanji fragment completion test could be directly linked to the conceptual component of the cues of this test, the contamination hypothesis would be superfluous. One way of establishing such a direct link would be to demonstrate that, under the same conditions, the LOP manipulation produces a significant effect when the cues are meaningful kanji fragments, but not when they are meaningless hiragana fragments. Experiment 2 was an investigation of this possibility.

Finally, the effect of a conceptual manipulation on a perceptual test can be attributed not only to a conceptual component in the test, but also to a perceptual component in the manipulation. In three experiments, Challis and Brodbeck (1992) found significant LOP effects on word fragment completion when subjects studied all the words in a list under the same study task (betweensubjects design, or within-subjects design with blocked lists) but not when the semantic and physical tasks varied randomly in the list (within subjects, with mixed lists). They suggested that when lists are unmixed, the LOP manipulation might affect not only conceptual, but also perceptual processing. For example, performing the physical task on every word in the list could disrupt the basic perceptual processing of the words, yielding lower performance on the physical condition. In Experiment 1, the study lists were unmixed, and hence, the possibility of a perceptual effect of the LOP manipulation should be considered. In Experiment 2, LOP was manipulated with mixed lists.

\section{EXPERIMENT 2}

One objective of Experiment 2 was to investigate the three foregoing problems. First, the possibility that the kanji fragment completion test can be simultaneously affected by perceptual and conceptual manipulations was investigated by observing not only the effect of the LOP manipulation, but also the effect of a script manipulation. Second, the effect of the LOP manipulation on the kanji fragment completion test was directly compared with that on a hiragana fragment completion test
(Figure $1 \mathrm{~b}$ ). If the LOP manipulation produces a significant effect on the kanji but not on the hiragana test, the assumption that the LOP effect on the kanji test is a consequence of the conceptual component of its ideographic cues would be strengthened, and the alternative contamination explanation would be weakened. Third, LOP was manipulated under mixed list conditions in order to investigate the possibility that the significant $L O P$ effect on the kanji fragment completion test in Experiment 1 was due to a perceptual effect of this manipulation under unmixed list conditions.

A second objective of Experiment 2 was to investigate the subdivision assumption - that is, the idea that it is possible to distinguish between types of perceptual processing and types of conceptual processing (see, e.g., Roediger and McDermott, 1993). As said before, the perceptual side of this assumption has been supported by Weldon and Roediger's (1987) finding that words produce more priming than pictures on a word fragment test but the opposite occurs on a picture fragment test. Experiment 2 was performed in an attempt to further support the subdivision assumption by obtaining a similar dissociation between the kanji and hiragana fragment completion tests as an effect of script.

A final objective of Experiment 2 was to investigate the effect of the LOP and script manipulations on a new implicit conceptual test, the sentence completion test, and on its explicit version, the sentence cued recall test (a similar explicit sentence test was used by Shimamura \& Squire, 1988). The cues of the sentence completion test are not questions, as in the general knowledge test (e.g., What group of animals became extinct in prehistoric times?), but sentences with a blank (e.g., When Peter entered the museum he saw the skeleton of a ). In Experiment 2, subjects were required to write the answers of the sentence completion and sentence cued recall tests in hiragana, and consequently, here these tests are sometimes called the hiragana sentence completion test and the hiragana sentence cued recall test.

\section{Method}

Subjects and Design. The subjects were 72 undergraduates, who participated voluntarily in the experiment. The design had two between-subjects factors- test type (hiragana fragment completion, kanji fragment completion, sentence completion, sentence cued recall) and study script (hiragana, kanji)-and two withinsubjects factors - item type (semantic, physical, nonstudied) and retention interval ( $30 \mathrm{~min}, 1$ week). The results of the retention interval manipulation will not be reported or discussed here for the same reasons as in Experiment 1. The subjects were equally distributed among the between-subjects conditions.

Materials. The critical materials were based on 96 words selected from Japanese word fragment completion norms (Mori \& Ohta, 1991; Ohta, Komatsu, Harada, \& Terasawa, 1991). The h1ragana fragments were those provided by the norms, with the exception of some modified on the basis of the results of a pilot study, and the kanji fragments were constructed as in Experiment 1 . With few exceptions, both types of fragments could be completed only with the target words. The cues of the hiragana sentence completion test were sentences with a blank that could be 
completed with one word. Target words were among the best possible completions, but several other words could also fit the meaning of the sentences. The baseline level of the cues of the three implicit tests was examined in two pilot studies, and the cues that were too easy (baseline above 0.50 ) or too difficult (baseline below 0.10 ) were modified accordingly.

The set of 96 target words and corresponding cues was randomly divided into six sets of 16 items each. The subjects studied four sets and were tested on two of them, plus a set of nonstudied items. The other two studied sets and one nonstudied set were tested in a delayed condition whose results, as said before, will not be reported here. In addition, 18 words were selected from the same sources to be used as study fillers ( 4 primacy; 8 recency), and warming up cues in the tests ( 6 words).

Procedure. The experiment was introduced to the subjects as a study concerning the mental processes involved in reading. The subjects had 5 sec to perform the study task on each word. For each subject, two sets of words were studied under a semantic study task, and two under a physical study task. A symbol to the right of each word indicated whether a semantic or a physical task had to be performed. The words of these sets were listed in a random order, so subjects did not know, before uncovering each item, whether they had to perform a semantic or a physical task. The semantic task was the same as that in Experiment 1: to think of a sentence by using the word, and to indicate the difficulty of doing so on a 5-point scale. The physical task consisted of counting the number of line intersections in the hiragana words, or the number of horizontal strokes in the kanji words. These two tasks involve approximately the same time and difficulty.

After the study phase, subjects listened to a lecture for $30 \mathrm{~min}$ and then received one of the four tests. The instructions for the implicit tests asked subjects to complete each cue with the first appropriate word that came into their minds. The instructions for the explicit sentence test told subjects to use the incomplete sentences as cues to remember studied words. The time allowed for each item was $5 \mathrm{sec}$ in the study phase and $10 \mathrm{sec}$ in the test phase. In both phases, a bell rang to indicate to the subjects when the time allowed for that item had ended and that they had to start with the item below. Also, subjects used a cover sheet to avoid looking ahead to new items, and were instructed not to go back to an item once it had been passed.

\section{Results and Discussion}

The results of Experiment 2 are presented in Table 2. The priming scores in this table indicate that priming in the three implicit tests was considerable when the script at study and at test matched, and very small when they mismatched. In the hiragana fragment completion test, priming was significant for words studied in hiragana [semantic, $F(1,8)=15.74, M S_{\mathrm{e}}=.125 ;$ physical, $F(1,8)=$ $\left.10.95, M S_{\mathrm{e}}=0.087\right]$, but not for those studied in kanji $(F \mathrm{~s}<1)$. In the kanji fragment completion test, in contrast, priming was significant for words studied in kanji [semantic, $F(1,8)=28.37, M S_{\mathrm{e}}=0.63$; physical, $F(1,8)=$ $12.61, M S_{\mathrm{e}}=0.29$ ], but not for those studied in hiragana $(F \mathrm{~s}<1.1)$. As in the hiragana fragment completion test, priming in the hiragana sentence completion test was significant in the hiragana [semantic, $F(1,8)=18.18$, $M S_{\mathrm{e}}=0.21$; physical, $\left.F(1,8)=6.83, M S_{\mathrm{e}}=0.08\right]$, but not in the kanji condition [semantic, $F<1$; physical, $F(1,8)=$ $\left.2.91, M S_{\mathrm{e}}=0.02\right]$. In contrast to priming, explicit memory scores in the hiragana sentence cued recall test did not reliably vary according to study script conditions but according to LOP conditions: after semantic study, explicit memory scores were significant in both the hiragana $\left[F(1,8)=17.81, M S_{\mathrm{e}}=0.48\right]$ and the kanji $[F(1,8)$ $\left.=23.93, M S_{\mathrm{e}}=0.44\right]$ conditions, but after physical study, neither was significant [hiragana, $F<1$; kanji, $\left.F(1,8)=3.84, M S_{\mathrm{e}}=0.07\right]$.

The LOP manipulation affected the kanji $[F(1,16)=$ $4.170, M S_{\mathrm{e}}=0.04, p<.06 ;$ kanji study condition $[F(1,8)=$ 9.63, $\left.M S_{\mathrm{e}}=0.07, p<.02\right]$, but did not reliably affect the hiragana fragment completion test $(F<1)$. The LOP effect was not significant in the hiragana sentence completion test $(F<1)$, but was highly significant in its explicit version $\left[F(1,16)=14.35, \mathrm{MS}_{\mathrm{e}}=0.43\right]$.

As Figure 2 clearly shows, the script manipulation affected the hiragana fragment completion test $[F(1,16)=$ 3.122, $M S_{\mathrm{e}}=0.17, p=.0962$; semantic condition, $\left.F(1,16)=6.38, M S_{\mathrm{e}}=0.10, p<.02\right]$, the kanji fragment completion test $\left[F(1,16)=8.53, M S_{\mathrm{e}}=0.62\right]$, and the sentence completion test $\left[F(1,16)=7.75, M S_{\mathrm{e}}=0.14\right]$, but did not significantly affect the sentence cued recall test $(F<1)$. It is evident from Figure 2 that the script manipulation produced a crossover dissociation between the word and kanji fragment completion tests: in the word fragment completion test, priming was larger for words studied in hiragana than for those studied in kanji, whereas the opposite occurred in the kanji fragment completion test [test $\times$ script interaction: $F(1,32)=$ $\left.11.31, M S_{\mathrm{e}}=0.73, p<.002\right]$.

Experiment 2 provided the three findings necessary to thoroughly ground the conclusion of Experiment 1 that

Table 2

Experiment 2: Proportion of Correct Completions in the Semantic, Physical, and Nonstudied Conditions, Level-of-Processing (LOP) Effect (Semantic Minus Physical), and Script Effect (Within-Script Minus Between-Script) as a Function of Tests and Study Script

\begin{tabular}{|c|c|c|c|c|c|c|}
\hline \multirow[b]{2}{*}{ Test } & \multirow[b]{2}{*}{ Study } & \multicolumn{3}{|c|}{ Condition } & \multicolumn{2}{|c|}{ Effect } \\
\hline & & Semantic & Physical & Nonstudied & LOP & Script \\
\hline Hiragana fragment & hiragana & .58 & .55 & .41 & .03 & .15 \\
\hline completion & kanji & .33 & .33 & .32 & .00 & \\
\hline Kanji fragment & hiragana & .42 & 40 & .36 & .02 & .26 \\
\hline completion & kanji & .77 & .65 & .40 & .12 & \\
\hline Hiragana sentence & hiragana & .47 & .39 & .26 & .08 & .12 \\
\hline completion & kanji & .28 & .31 & 25 & -.03 & \\
\hline Hiragana sentence & hiragana & .47 & .22 & .14 & .25 & -.02 \\
\hline cued recall & kanji & .43 & .24 & .12 & .18 & \\
\hline
\end{tabular}




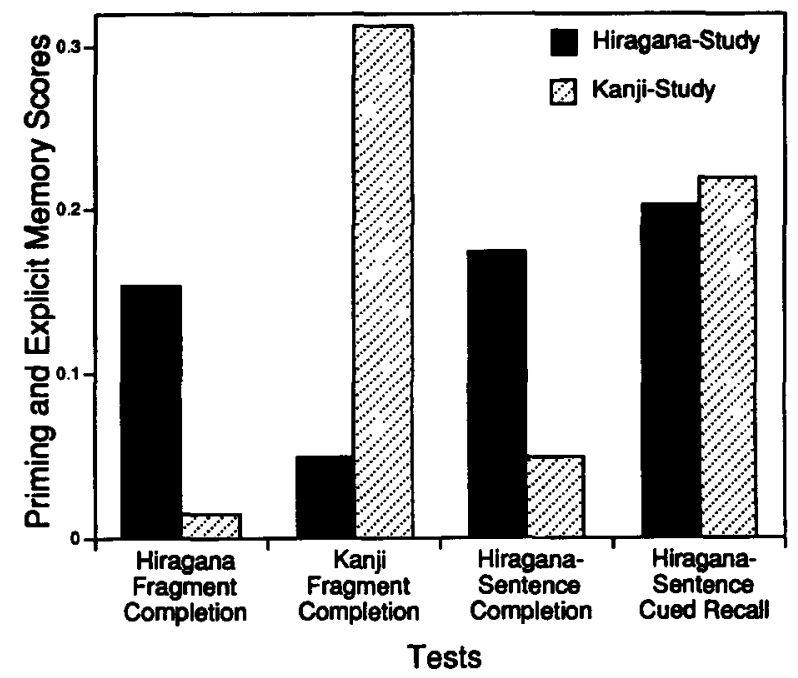

Figure 2. Experiment 2: Effects of a hiragana-kanji script shift collapsed over semantic and physical study conditions.

the kanji fragment completion test reflects a mixture of perceptual and conceptual processing. First, the kanji fragment completion test was simultaneously affected by both the LOP and the script manipulations. Second, the LOP manipulation affected the kanji fragment test but not the hiragana fragment test. This second result establishes a direct relation between the LOP effect and the ideographic nature of kanji fragment cues. As with the conceptual effects on implicit conceptual tests (see, e.g., Blaxton, 1989; Challis \& Sidhu, 1993; Hamann, 1990; Srinivas \& Roediger, 1990), this effect can be attributed to the conceptual properties of the cues, and no assumption of contamination by explicit retrieval strategies is needed. In the terminology of Tulving and Schacter (1990), the LOP and script effects suggest that the kanji fragment completion test reflects both perceptual priming and conceptual priming. Third, the LOP effect on the kanji test was not eliminated by the use of mixed lists, suggesting it was not a perceptual effect of the LOP manipulation under the unmixed lists conditions of Experiment 1.

The crossover dissociation between the hiragana fragment and kanji fragment completion tests as an effect of the hiragana/kanji manipulation parallels the one found by Weldon and Roediger (1987) between a word test and a picture test as an effect of a word/picture manipulation and provides further support for the idea that it is possible to distinguish between types of perceptual processing (subdivision assumption). If Weldon and Roediger's (1987) dissociation suggested a distinction between perceptual processing of words and pictures, the dissociation under discussion suggests a distinction between perceptual processing of hiragana and kanji scripts.

A final objective of Experiment 2 was to investigate the effects of the LOP and script manipulations on the new sentence completion test and on its explicit version, the sentence cued recall test. The LOP and script manipulations produced a double dissociation between the two tests: the LOP manipulation affected the explicit but not the implicit test, whereas the script manipulation affected the implicit but not the explicit test. This double dissociation corroborates the implicit nature of the new sentence completion test on the basis of the retrieval intentionality criterion (Schacter, Bowers, \& Booker, 1989), which states that explicit retrieval on an implicit test can be ruled out when it can be dissociated from an explicit test based on the same nominal cues and differing only in the instructions. The finding that the LOP effect was larger in the explicit than in the implicit sentence completion test [test $\times$ LOP interaction, $F(1,32)=$ $\left.7.91, M S_{\mathrm{e}}=0.164, p<.009\right]$ confirms the idea that explicit instructions tend to increase conceptual processing (see, e.g., Roediger, Weldon, \& Challis, 1989) and extends similar findings obtained with the general knowledge test (present Experiment 1; Challis \& Sidhu, 1993).

The results of the hiragana sentence completion test were surprising. First, unlike standard implicit conceptual tests (see, e.g., Challis \& Sidhu, 1993; Hamann, 1990; Srinivas \& Roediger, 1990), the sentence test did not show a significant LOP effect. This inconsistency could stem from differences in statistical power, but it could also reflect differences between the tests. For example, while a knowledge question like What group of animals became extinct in prehistoric times? implies that there is only one answer (e.g., dinosaur), because of its wording, a sentence completion cue such as When Peter entered the museum, he saw the skeleton of a seems to accept several different comple-

tions (e.g., bird, reptile, hominid, dinosaur, monkey, etc.). It is possible to speculate that the process of retrieving a specific word from semantic memory requires more conceptual processing than the process of generating candidate words to fill a blank in a sentence. Accordingly, in the same way that it has been suggested that the word fragment completion test is "more conceptual" than the perceptual identification test (see, e.g., Roediger \& Blaxton, 1987; Schwartz, 1989; Weldon, 1991), the sentence completion test could be "less conceptual" than the general knowledge test.

Second, the hiragana sentence completion test showed a significant script effect. This effect was completely unexpected, because a significant effect of perceptual manipulation on an implicit conceptual test has never been reported. On the contrary, when perceptual manipulations such as modality (Challis \& Sidhu, 1993; Srinivas \& Roediger, 1990) and typography (Blaxton, 1989) study-test shifts were investigated on implicit conceptual tests, no significant effects were found. The significant script effect on the sentence completion test is surprising, because the script shift seems to affect only perceptual processing, whereas the sentence completion test seems to involve only conceptual processing. One possible explanation is that the script manipulation affects also conceptual processing, but this idea is inconsistent with the null effect of script on the sentence cued recall test, which, as indicated by its marked sensitivity 
to LOP, seems to involve a large amount of conceptual processing. The alternative explanation that the sentence completion test reflects not only conceptual but also perceptual processing is more convincing, but it has a problem: How can the sentence completion test involve perceptual processing if its cues do not provide any information about the perceptual structure of the targets?

One answer to this problem is that the perceptual component of the hiragana sentence completion test is not located in the sentence cues but in the instruction to write the answers in hiragana. For example, instead of generating and selecting words only on the basis of their meanings, and then writing the chosen words in hiragana, subjects might have tried to "generate words in hiragana." In such a case, subjects in the hiragana study condition would have tended to produce more studied words as completions than would subjects in the kanji study condition. This effect would not occur when instructions were explicit, because subjects in the kanji condition would try to retrieve studied items, even if they saw them in a different script. Thus, the significant script effect on the hiragana sentence completion test can be interpreted as indicating that this test reflects not only conceptual processing but also perceptual processing. While the significant LOP effect on the kanji fragment completion test suggests that an implicit perceptual test can involve a considerable amount of conceptual processing, the unexpected significant script effect on the hiragana sentence completion test suggests that an implicit conceptual test can involve an important quantity of perceptual processing. Therefore, these two findings complement each other to provide a strong support for the mixture assumption.

\section{GENERAL DISCUSSION}

Overall, the reported results support the mixture and subdivision assumption of the processing view. The mixture assumption is buttressed first by the simultaneous significant effects of LOP and script on the kanji fragment completion test. We assume that the significant LOP effect stems from the conceptual component of kanji fragments, rather than from a contamination by explicit retrieval strategies, because it did not occur with meaningless hiragana fragments. Second, the mixture assumption is also supported by what is probably the first report of a significant perceptual effect (script) on an implicit conceptual test (sentence completion). The subdivision assumption is supported by a crossover dissociation between hiragana and kanji fragment completion tests as an effect of a kanji/hiragana manipulation, which suggests a distinction between perceptual processing of kanji and hiragana characters.

In addition, the present research raises questions for future research, in relation to the mixture assumption, the subdivision assumption, and script manipulation. One issue regarding the mixture assumption is whether to conceptualize the mixture of perceptual and concep- tual processing in terms of one continuum or in terms of two continua. Originally, the processing view argued that tests could be arranged along a continuum reflecting differential amounts of perceptual or conceptual processing (see, e.g., Roediger \& Blaxton, 1987; Roediger, Weldon, \& Challis, 1989). This idea implies that tests that are more conceptual (i.e., more sensitive to conceptual manipulations) should be less perceptual (i.e., less sensitive to perceptual manipulations), and vice versa. Recently, however, the processing view has proposed that perceptual and conceptual processing are two separate dimensions that do not necessarily trade off against each other (Roediger \& Challis, 1992; Roediger \& McDermott, 1993; Weldon, 1991). A comparison of LOP and script effects on the hiragana and kanji fragment completion tests in Experiment 2 provides support for this new conception. Since the LOP effect was larger on the kanji than on the hiragana test, the single-continuum view predicts that the script effect should be smaller on the former than on the latter, but the tendency was in the opposite direction. The kanji test appeared, at the same time, more conceptual and more perceptual than the hiragana test, a result more compatible with the twocontinua notion. Another issue about the mixture assumption is whether it is possible to manipulate the amount of perceptual and conceptual processing tapped by a memory test. In the case of the kanji fragment completion test, for example, it is possible to manipulate the amount of conceptual processing by deleting or retaining meaningful kanji parts in the fragments (Cabeza \& Takahashi, 1994).

Concerning the subdivision assumption, as Roediger and McDermott (1993, p. 118) said, "just as we can distinguish different sorts of perceptual processes and use them to make principled predictions on implicit perceptual tests (as in Weldon \& Roediger, 1987, Experiment 4) we need to make finer grained distinctions in the conceptual domain too." Initial evidence in the conceptual domain was provided by Cabeza's (1994) finding of a dissociation between two implicit conceptual tests (category association and free association), but further research seems warranted.

As for the script manipulation, although it was provisionally classified as a surface form shift, its effects are very different from previously reported effects. While standard surface form shifts (e.g., typography case) typically produce very weak effects - often nonsignificant even on implicit perceptual tests (see, e.g., Carr, Brown, \& Charalambous, 1989; Clarke \& Morton, 1983; Levy \& Kirsner, 1989; Rajaram \& Roediger, 1993; Scarborough, Cortese, \& Scarborough, 1977) - and leave a considerable amount of between-form priming untouched (see, e.g., Kirsner \& Dunn, 1985; Roediger \& Blaxton, 1987), the script shift produced a strong effect and eliminated cross-script priming almost completely. In the word fragment completion test, Roediger and Blaxton estimated that an average priming of 0.27 is markedly reduced to 0.07 by symbol type shifts and to 0.02 by lan- 
guage shifts, but only slightly attenuated to 0.23 by typography shifts. In Experiment 2, the script manipulation decreased the average priming in the hiragana and kanji fragment completion test from 0.23 to 0.03 ; that is, its effect resembles symbol type and language shifts, rather than typography shifts. Moreover, cross-script priming was almost null even in the kanji fragment completion and sentence completion tests, which are assumed to reflect conceptual processing. On the other hand, the script shift did not affect explicit performance in the sentence cued recall test.

One possible explanation of why script shift is as powerful as symbol type and language shifts is that, like words and pictures (see, e.g., Kroll \& Potter, 1984) and different languages in bilinguals (see, e.g., Smith, 1991), hiragana and kanji scripts are lexically independent. This idea is supported by pathological dissociations between kana and kanji processing: some aphasic (see, e.g., Sasanuma, 1974, 1975; Sasanuma \& Fujimura, 1971) alexic, and agraphic (see Paradis et al., 1985) patients are selectively impaired in kana processing, whereas others are selectively impaired in kanji processing. It has been suggested that while kana is primarily processed through a phonological route (grapheme-to-sound-to-meaning), kanji is primarily processed through a visual route (grapheme-to-meaning-to-sound) (e.g., Sasanuma, 1974; Yamadori, 1975). Greater impairment of kana processing has been associated with lesions in the third frontal gyrus of the left hemisphere and neighboring areas, as well as greater impairment of kanji processing, with lesions in the posterior parts of the second and third temporal gyri (Sasanuma \& Monoi, 1975).

If hiragana and kanji words involve different lexical representations, the script effect could be interpreted in the same way as the effect of language shifts in bilinguals. Language shifts typically eliminate between-language priming but do not affect recall performance (for a review, see Roediger \& McDermott, 1993; Smith, 1991). This evidence has been explained as follows: in bilinguals, different languages have separate lexical representations but common semantic representations; priming is disrupted by translations, because it relies on lexical-level representations, ${ }^{3}$ whereas recall is immune to them, because it is based on language-free semantic representations (Smith, 1991). Analogously, the script shift might eliminate priming because hiragana and kanji words involve different lexical representations, but do not affect recall in the explicit sentence test because hiragana and kanji words have the same semantic representations.

However, why was there no cross-script priming in the kanji fragment completion test and sentence completion tests, which are assumed to reflect conceptual processing? Between-form priming has been attributed to a transfer of conceptual processing (see, e.g., Bassili, Smith, \& MacLeod, 1989; Roediger \& Blaxton, 1987), and hence, it should occur on tests sensitive to conceptual processing. One possible answer is that, like priming in implicit perceptual tests (see, e.g., Weldon, 1991;
Weldon \& Jackson-Barret, 1993), priming in implicit conceptual tests requires lexical access and hence is eliminated by script shifts. Since the performance on the explicit sentence test was not affected by the script shift, it would be necessary to assume that conceptual processing in implicit conceptual and explicit conceptual tests involves different mechanisms, an idea that could be harmonized with multiple memory system views. For example, Tulving and Schacter's (1990) model could incorporate the assumption that access to script-specific lexical representations is necessary for conceptual priming, but not for explicit memory, and Squire's (1987) view could postulate that the script shift affects nondeclarative memory, but not declarative memory. Regardless of which theoretical approach is taken, further research is necessary in order to understand why the script manipulation affected implicit tests, both perceptual and conceptual, but not an explicit test.

To summarize- the reported results support the mixture and subdivision assumptions, and they suggest some problems for future research concerning these two assumptions and the manipulation of Japanese scripts.

\section{REFERENCES}

Bassili, J. N., Smith, M. C., \& MaCLeOd, C. M. (1989). Auditory and visual word-stem completion: Separating data-driven and conceptually-driven processes. Quarterly Journal of Experimental Psychology, 41A, 439-453.

BLAXTON, T. A. (1989). Investigating dissociations among memory measures: Support for a transfer-appropriate processing framework. Journal of Experimental Psychology. Learning, Memory, \& Cognition, 15, 657-668.

Bowers, J. S., \& SChaCTER, D. L. (1990). Implicit memory and test awareness. Journal of Experimental Psychology: Learning, Memory, \& Cognition, 16, 404-416.

Brown, H., Sharma, N. K., \& Kirsner, K. (1984). The role of script and phonology in lexical representation. Quarterly Journal of Experimental Psychology, 36A, 491-505.

CABEzA, R. (1994). A dissociation between two implicit conceptual tests supports the distinction between types of conceptual processing. Psychonomic Bulletin \& Review, 1, 505-508.

Cabeza, R., \& OHTA, N. (1993). Dissociating conceptual priming, perceptual priming, and explicit memory. European Journal of Cognitive Psychology, 5, 35-53

Cabeza, R., \& Takahashi, H. (1994). Priming on single-kanji fragments: Towards the study of different kinds of priming on the same memory test. Tsukuba Psychological Research, 16, 75-82.

Carr, T. H., Brown, J. S., \& Charalambous, A. (1989). Repetition and reading: Perceptual encoding mechanisms are very abstract but not very interactive. Journal of Experimental Psychology. Learning, Memory, \& Cognition, 15, 763-778.

Challis, B. H., \& Brodbeck, D. R. (1992). Level of processing affects priming in word fragment completion. Journal of Experimental Psychology: Learning, Memory, \& Cognition, 18, 595-607.

Challis, B. H., \& SidHu, R. (1993). Dissociative effect of massed repetition on implicit and explicit measures of memory. Journal of Experimental Psychology: Learning, Memory, \& Cognition, 19, 115-127.

Clarke, R., \& Morton, J. (1983). Cross modality facilitation in tachıstoscopic word recognition. Quarterly Journal of Experimental Psychology, 35A, 79-96.

GraF, P., \& MANDleR, G. (1984). Activation makes words more accessible, but not necessarily more retrievable Journal of Verbal Learning \& Verbal Behavior, 23, 553-568.

GRaf, P., \& RYAN, L. (1990). Transfer-appropriate processing for im- 
plicit and explicit memory. Journal of Experimental Psychology Learning. Memory, \& Corgnition, 16, 978-992.

Graf, P., SQuire, L. R., \& Mandler, G. (1984). The information that amnesic patients do not forget. Journal of Experimental Psychology: Learning. Memory; \& Cognition, 10, 164-178.

HAMANN, S. B. (1990). Level-of-processing effects in conceptually driven implicit tasks. Journal of Experimental Psychology: Learning. Memory. \& Cognition, 16, 970-977.

JACOBY, L. L. (1983). Remembering the data: Analyzing interactive processes in reading. Journal of Verbal Learning \& Verbal Behav. ior. 22, 485-508.

JACOBY, L. L., \& HollingSheAD, A. (1990). Toward a generate/recognize model of performance on direct and indirect tests of memory Journal of Memory \& Language, 29, 433-454.

KIRSNF.R, K., \& DUNN, J. (1985). The perceptual record: A common factor in repetition priming and attribute retention. In M. I. Posner \& O. S. M. Marin (Eds.), Attention and performance XI (pp. 547. 566). Hillsdale, NJ: Erlbaum

KIRSNER, K., \& SMITH. M. C. (1974). Modality effects in word identification. Memory \& Cognition, 2, 637-640.

KoKLRITSU KoKUGO KenKYUJOU (1983). Koukou kyoukasho no goi chousa [The National Language Research Institute. Studies on the vocabulary of senior high-school textbooks]. Tokyo: Tokyo-Shoseki: Author.

Kom^tsu, S.-I., \& NaITo, M. (1992). Repetition priming with Japanese Kana scripts in word-fragment completion. Memory \& Cognition, 20, 160-170.

Kомл isu, S.-I., \& Oнта, N. (1984). Priming effects in word fragment completion for short and long retention intervals. Japanese $P s y$ chological Research, 26, 194-200.

KROI.1., J. F., \& PotTER, M. C. (1984). Recognizing words, pictures and concepts: A comparison of lexical, object and reality decision. Journal of Experimental Psychology: Learning. Memory. \& Cognition, 23, 39-66.

LEVy, B. A., \& KIRSNer, K. (1989). Reprocessing text: Indirect measures of word and message level processes. Journal of Experimental Psychology: Learning, Memory. \& Cognition, 15, 407-417.

Masson, M. E. J. (1984). Memory for the surface structure of sentences: Remembering with and without awareness. Journal of Experimental Psychology: Learning, Memory, \& Cognition, 12, 295. 306.

MORI, N., \& OHTA, N. (1991). A norm of guessing rate of the wordfragment completion task, II. Tsukuba Psychological Research, 13, 135-140.

Morris, C. D., Bransford, J. D., \& Franks, J. J. (1977). Levels of processing versus transfer appropriate processing. Journal of Verbal Learning \& Verbal Behavior, 16, 519-533.

NEI.SON, A. N. (1974). The modern reader's Japanese-English character dictionary. Tokyo: Tuttle.

Ohta. N., Komatsu, S.-I., Harada, E., \& Terasawa, T. (1991). A norm of guessing rate of the word-fragment completion task, I. Tsukuba Psychological Research, 13, 13 I-134.

Paradis, M.. Hagiwara, H.. \& Hildebrandt, N. (1985). Neurolinguistic aspects of the Japanese writing system. Orlando, FL: Academic Press.

Rajaram, S., \& RoEdiger, H. L., III (1993). Direct comparison of four implicit memory tests. Journal of Experimental Psychology: Learning. Memory. \& Cognition, 19, 765-776.

RAPPOLD, V. A., \& HASHTROUd, S. (1991). Does organization improve priming? Journal of Experimental Psychology: Learning. Memory. \& Cognition, 17, 103-114.

Richardson-Klavehn, A., \& Bjork, R. A. (1988). Measures of memory. Annual Review of Psychology, 30, 519-523.

ROEDiger, H. L., III, \& Blaxton, T. A. (1987). Retrieval modes produce dissociations in memory for surface information. In D. Gorfein \& R. R. Hoffman (Eds.), Memory and cognitive processes. The Ebbinghaus Centennial Conference (pp. 349-379). Hillsdale, NJ: Eribaum.

Roediger, H. L., III. \& Challis, B. H. (1992). Effects of exact repetition and conceptual repetition on frec recall and primed word-fragment completion. Journal of Experimental Psychology: Learning. Mem ory, \& Cognition, 18, 3-14

ROFDIGFR, H. L., III, \& MCDFRMOTT, K. B. (1993). Implicit memory in normal human subjects. In F. Boller \& J. Grafman (Eds.), Handhook of neuropsychology (Vol. 8, pp. 63-130). Amsterdam: Elsevier.

Roediger, H. L., III, Srinivas, K., \& Weldon, M. S. (1989). Dissociations between implicit measures of retention. In S. Lewandowsky. J. C. Dunn, \& K. Kirsner (Eds.), Implicil memory: Theorefical issues (pp. 67-84). Hillsdale, NJ: Erlbaum

Roediger, H. L., III, Weldon, M. S., \& Challis, B. H. (1989) Explaining dissociations between implicit and explicit measures of retention: A processing account. In H. L. Roediger III \& F. I. M. Craik (Eds.), Varieties of memony and consciousness: Essays in honor of Endel Tulving (pp. 3-41). Hillsdale, NJ: Erlbaum

Roediger, H. L., III, Weldon, M. S., Stadlek, M. L., \& Riegler, G. L. (1992). Direct comparison of two implicit memory tests: Word fragment and word stem completion. Journal of Experimental Psychology. Learning, Memory, \& Cognition, 18, 1251-1269.

SASANLima, S. (1974). Kanji versus kana processing in alexia with transient agraphia: A case report. Cortex, 10. 89-97.

SASANLMA. S. (1975). Kana and kanji processing in Japanese aphasics. Brain \& Language, 2, 360-383.

Sasanima, S., \& FLJimura, O. (1971). Selective impairment of phonetic and non-phonetic transcription of words in Japanese aphasic patients: Kana vs. kanji in visual recognition and writing. Cortex, 7 , $1-18$.

Sasanuma, S., \& Monol, H. (1975). The syndrome of gogi (wordmeaning) aphasia: Selective impairment of kanji processing. Neurology, 25, 627-632.

Scarborough, D. L., Cortese, C., \& Scarborough, H. S. (1977). Frequency and repetition effects in lexical memory. Journal of Experimental Psychologl: Human Perception \& Performance, 3, $1-17$.

SCHACTER, D. L. (1987). Implicit memory: History and current status. Journal of Experimental Psychology: Learning. Memory: \& Cugnition, 13, 501-518.

SChACTER, D. L., Bowr.RS, J., \& Booker. J. (1989). Intention, awareness, and implicit memory. In H. L. Roediger III \& F. I. M. Craik (Eds.), Implicit memory: Theoretical issues (pp. 47-65). Hillsdale, NJ: Erlbaum

SCHWARTZ, B. L. (1989). Effects of generation on indirect measures of memory. Journal of Experimental Psychology: Learning. Memory; \& Cognition, 15, 1119-1128

Shimamura, A. P. (1986). Priming effects in amnesia: Evidence for a dissociable memory function. Quarterly Journal of Experimental Psychology, 38A, 619-644

Shimamura, A. P., \& Squire, L. R. (1988). Long-term memory in amnesia: Cued recall, recognition memory, and confidence ratings. Journal of Experimental Psychology. Learning. Memory. \& Cognition. 14, 763-770.

Sмітн, M. C. (1991). On the recruitment of semantic information for word fragment completion: Evidence from bilingual priming. Journal of Experimental Psychology: Learning, Memory, \& Cognition. 17, 234-244

SQuiRE, L. R. (1987). Memory and brain. New York: Oxford University Press.

SqliRe, L. R., Shimamura, A. P., \& Grar, P. (1987). Sirength and duration of priming effects in normal subjects and amnesia patients Neuropsychologia, 25, 195-210.

SRINivas, K., \& Roediger, H. L., III (1990). Classifying implicit memory tests: Category association and anagram solution. Journal of Memory \& Language, 29, 389-412.

Tulving, E., \& SChaCter, D. L. (1990). Priming and human memory systems. Science, 247, 301-305.

WELDON, M. S. (1991). Mechanisms underlying priming on perceptual tests. Journal of Experimental Psychology: Learning. Memory: \& Cognition, 17, 526-541

WFI DON, M. S., \& JACKSON-BARRET, J. L. (1993). Why do pictures produce priming on the word-fragment completion test? A study of encoding and retricval factors. Memory \& Cognition. 21, 519 . 528 . 
Weldon, M. S., \& Roediger, H. L., III (1987). Altering retrieval demands reverses the picture superiority effect. Memory \& Cognition, $15,269-280$.

YAMADORI, A. (1975). Ideogram reading in alexia. Brain, 98, 231238.

\section{NOTES}

1. In a broader sense, implicit memory tests include not only measures of priming, but also measures of skill learning and habit acquisition (see Squire, 1987).

2. It is important to notice, however, that, if the whole cue is not considered, the probability of completing the fragment of one kanji with the particular kanji used in the word is very low. For example, the fragment of the first kanji in Figure 1 can be completed by the kanji of letter, but also by several dozens of other kanji (Nelson, 1974).

3. The idea that prıming on implicit perceptual tests requires lexical access is supported, for example, by Weldon's (1991) finding that anagrams (e.g., tripocs) prime the completion of word fragments (e.g., tr_p_cs) when the anagrams are mentally transposed into words at study (e.g., tropics), but not when they are studied as anagrams (e.g., tripocs), even if the amount of perceptual overlap is the same in both conditions.

(Manuscript received December 9, 1993; revision accepted for publication April 28, 1994.) 